\title{
Editorial Cultura de paz
}

\begin{abstract}
Raimundo Caviedes Hoyos ${ }^{1}$
Sociólogo Universidad de La Salle, Bogotá. Magíster Filosofía de la Universidad Santo Tomás, Bogotá.

Con la edición del presente volumen de la revista, dedicado a la divulgación de algunas formas alternas al empleo de la fuerza, la agresión y la violencia como medios de solución de conflictos, la Facultad de Ciencias Jurídicas y Sociales de la Universidad Simón Bolívar pretende contribuir a los procesos de construcción de una cultura de paz en Colombia.
\end{abstract}

En Colombia, además de la implementación de acuerdos que dieron fin a más de medio siglo de conflicto armado con las Fuerzas Armadas Revolucionarias de Colombia -FARC-, algunos sectores sociales han venido realizando acciones y políticas complementarias para la construcción de una cultura de paz que dé fin a la absurda forma de dirimir los conflictos de forma violenta, sin dejar de reconocer por ello la necesaria permanencia del conflicto como elemento que acompaña a toda sociedad. Lo que hace la diferencia entre una cultura violenta y una cultura de paz es la forma en que estos son tratados y resueltos. A una cultura violenta corresponden formas de gobierno y de convivencia basadas en la dictadura y el totalitarismo, mientras a la cultura de paz corresponden gobiernos democráticos.

Sin embargo, el gobierno democrático, por sí solo o entendido simple y llanamente como forma de acceder al poder por la voluntad de las mayorías a través de las elecciones, no garantiza una convivencia pacífica. En Colombia como en la mayoría de los países "democráticos", muchos conflictos se siguen tratando en forma violenta y por ello, a pesar de la terminación de una gran parte del conflicto político armado, persiste la cultura de la violencia.

Para lograr avanzar efectivamente en la construcción de una cultura de paz
JUSTICIA 
es necesario, en primer lugar, reconocer el conflicto y sus distintas formas de expresarse. En segundo término, intervenir las distintas formas de violencia y de su legitimación, especialmente tratándose de la violencia estructural y la cultural, y tercero, fomentar, divulgar y crear formas innovadoras para la resolución de estos conflictos.

De aquí lo oportuno para la consolidación de la paz en Colombia que resulta de la divulgación de libros y tratados como el presente, dedicados al arbitraje, la mediación y la conciliación que promueve el conocimiento y la discusión sobre distintas formas de resolver conflictos sin acudir a la violencia y la agresión. 